\title{
Synthesis and Characterization of Zinc Oxide Obtained by Combining Zinc Nitrate with Sodium Hydroxide in Polyol Medium
}

\author{
Dionisio da Silva Biron ${ }^{a, b^{*}}$, Venina dos $\operatorname{Santos}^{b}$ (i), Carlos Pérez Bergmann ${ }^{a}$ \\ ${ }^{a}$ Universidade Federal do Rio Grande do Sul (UFRGS), Escola de Engenharia Laboratório de \\ Materiais Cerâmicos, Porto Alegre, RS, Brasil. \\ ${ }^{b}$ Universidade de Caxias do Sul (UCS), Centro de Ciências Exatas e Tecnologia, Caxias do Sul, RS, Brasil.
}

Received: February 26, 2020; Revised: March 31, 2020; Accepted: April 20, 2020.

\begin{abstract}
Polyols as solvents are widely and successfully used in various methodologies to obtain zinc oxide nanostructures. One of the main reasons of using polyols is related to its capacity to prevent the agglomeration of $\mathrm{ZnO}$ nanoparticles during the synthesis and to promote a more stable colloidal solution of it. In this work it is presented, for the first time, the obtaining of nanostructured $\mathrm{ZnO}$ by a polyol mediated solvothermal synthesis using zinc nitrate as precursor. The combination of the zinc source with sodium hydroxide in a polyol medium with PVA as dispersing agent provided a simple process for obtaining nanostructured $\mathrm{ZnO}$. The zinc oxide nanostructures obtained were characterized by UV-visible, XRD, FESEM, TEM, DLS and BET. As result, was obtained a wurtzite phase with hexagonal structure with crystallite size of $12 \mathrm{~nm}$ and, according to TEM micrographs, an average size of $14 \mathrm{~nm}$, which was corroborated to other analyses.
\end{abstract}

Keywords: solvothermal synthesis, polyol medium, ethylene glycol, nanostructured $\mathrm{ZnO}$.

\section{Introduction}

The nanostructured $\mathrm{ZnO}$ is employed in several areas of industry and science due to its interesting properties and characteristics. It acts as antimicrobial agent ${ }^{1,2}$ and protector of epidermis ${ }^{3}$ in the health industry, as photocatalyst ${ }^{4}$, as pigments ${ }^{5}$ in the textile industry and, because of its luminescence and its semiconductor properties, it's applied in advanced ceramics ${ }^{6}$ and in solar cells ${ }^{7}$, respectively. The hexagonal wurtzite crystal structure (lattice parameters: $\mathrm{a}=0.3254 \mathrm{~nm}, \mathrm{c}=0.5215 \mathrm{~nm}$ ), a direct energy band gap of $3.37 \mathrm{eV}$, excitation binding energy of $60 \mathrm{meV}$ and high electron mobility are some of the properties of $\mathrm{ZnO}^{8}$.

With the aim to obtain nanostructures with different sizes and morphologies, such as $\operatorname{rod}^{9-11}$, spherical ${ }^{12}$, nanowire ${ }^{13}$ and nanosheets ${ }^{14}$, different physical ${ }^{15,16}$, chemical $^{17,18}$ and biological ${ }^{19,20}$ methods have been reported. However, for the most of them, the nanoparticulate system obtained tends to agglomerate due to both large specific surface area and high surface energy. Moreover, the formation of the $\mathrm{Zn}-\mathrm{O}-\mathrm{Zn}$ bond between the nanoparticles, that occurs because of the existence of water molecules in the synthesis process (solvent most commonly used), it's also a hindrance in promoting the desired system of $\mathrm{ZnO}$ nanoparticles ${ }^{21}$. Therefore, the removal of water or the use of another solvent for the synthesis may be able to avoid agglomeration of $\mathrm{ZnO}$ nanoparticles and promote a more stable colloidal $\mathrm{ZnO}$ solution. The solvothermal method with the use of polyols, multivalent alcohols with high boiling points, allows the reactions to occur at high temperatures with no need for high pressures or autoclaves, that's why it is a versatile and interesting method. It enables the control

*e-mail: birondionisio@gmail.com of the size and morphology of $\mathrm{ZnO}$ nanostructures ${ }^{22-26}$ and it's also used for obtaining doped $\mathrm{ZnO}$ nanoparticles s $^{27,28}$. The polyols more often used are ethylene glycol, diethylene glycol, tetraethylene glycol and glycerol ${ }^{29,30}$, whose boiling points are $197.3,245,285$ and $290^{\circ} \mathrm{C}^{31}$, respectively. Also, due to the elevate solubility capacity of the polyols, cheap and simple metal salts can be used as precursors ${ }^{32-34}$.

To comprehend how this method works we need to understand its four stages, Figure 1. In the first one, the solid precursor must be dissolved into a liquid polyol; in the second, the salt is reduced into small particles while the third step promotes a homogeneous nucleation process followed by the last stage, in which the nanostructures grow ${ }^{35}$.

In this paper, a polyol mediated solvothermal synthesis method was used to obtain $\mathrm{ZnO}$ nanostructured. The nanoparticulate system was characterized by different analyzes that proved that the simple method proposed can be successfully used to obtain $\mathrm{ZnO}$ particles with sizes in the range of $14 \mathrm{~nm}$.

\section{Material and Methods}

\subsection{Synthesis of zinc oxide}

The reagents used in this study were zinc nitrate hexahydrate $\left[\mathrm{Zn}\left(\mathrm{NO}_{3}\right)_{2} \cdot 6 \mathrm{H}_{2} \mathrm{O}\right]$ (INLAB, $99 \%$ purity) as zinc source, ethylene glycol anhydrous (Sigma-Aldrich, $99.8 \%$ purity) as solvent, polyvinyl alcohol (PVA, Vetec, $\mathrm{MM}=85 \mathrm{kDa}$ ) as dispersant and $\mathrm{NaOH}$ (Dinâmica, $99 \%$ purity) as $\mathrm{Zn}(\mathrm{OH})_{2}$ forming agent.

For the reactions, $25 \mathrm{~mL}$ of a solution of $\mathrm{NaOH} 1 \mathrm{~mol} \mathrm{~L}^{-1}$ in ethylene glycol was added dropwise to a stirred solution of $\mathrm{Zn}\left(\mathrm{NO}_{3}\right)_{2} \cdot 6 \mathrm{H}_{2} \mathrm{O}$ solution $\left(0.5 \mathrm{~mol} \mathrm{~L}^{-1}, 25 \mathrm{~mL}\right)$ in ethylene glycol as the stoichiometric ratio demands for the complete 
formation of $\mathrm{Zn}(\mathrm{OH})_{2}$. $0.05 \mathrm{~g}$ of PVA was added over that solution to provide a stable environment. Finally, the solution was heated in reflux at $140{ }^{\circ} \mathrm{C}$ for $4 \mathrm{~h}$.

The zinc oxide particulate system obtained was centrifuged at $8,000 \mathrm{rpm}$ for $15 \mathrm{~min}$ and washed with ethyl alcohol. The solid material was dried for $24 \mathrm{~h}$ at $80{ }^{\circ} \mathrm{C}$ for further characterization.

\subsection{Characterization of nanostructured zinc oxide}

For characterization in UV-Visible, the sample was firstly dispersed in ultrapure water $(100 \mathrm{ppm})$ and analyzed in a Genesys ultraviolet spectrophotometer, $10 \mathrm{mV}$, Thermo Spectronic. In addition, the optical band gap energy was determined by the Tauc plot, using the relationship proposed by Tauc, Davis, and Mott.

The X-ray diffraction patterns (XRD) of the nanostructured zinc oxide powder sample was obtained on a Shimadzu XRD-6000 X-ray diffractometer with $\mathrm{CuK} \alpha$ radiation and $\lambda=1.5406 \AA$. The crystallite sizes were determined by using the Scherrer equation:

$$
d=\frac{k \lambda}{\beta \cos (\theta)}
$$

where $d$ is the size of the crystallite, $k$ is the form factor (0.9), $\lambda$ is the wavelength of the radiation and $\beta$ is broadening of the Bragg's peaks $\left(\beta^{2}=\beta_{\text {sample }}^{2}-\beta_{\text {instrumental }}^{2}\right)$.

The silicon standard (MERCK, 99.99\%) was used to determine the instrumental broadening, Figure 2. The refinement of the diffractogram obtained was performed by the Rietveld method with the aid of Fullprof software, July 2017 version. The corresponding fitting equation (polynomial regression) is $y=a+b x+c x^{2}+d x^{3}$, where $y$ stands for the broadening in FWHM and $x$ is the angle in 2 $\theta . a, b, c$ and $d$ are the constants with values $0.13154,2.84904 \times 10^{4}$, $-7.55556 \times 10^{-6}$ and $9.91083 \times 10^{-8}$, respectively. In this study was neglected the strain broadening.

The morphology, particle size and particle size distribution (both analyzed with the aid of ImageJ software, $1.52 \mathrm{a}$ version) were observed in a field emission scanning electron microscope (FESEM) of the brand Tescan, equipment model MIRA3, and in a transmission electron microscope (TEM) JEM-1200 EX II, Jeol.

The powdered $\mathrm{ZnO}$ sample was suspended in absolute ethylene glycol anhydrous and exposed in ultrasound for $10 \mathrm{~min}$ at concentration of $100 \mathrm{ppm}$. Then, particle size

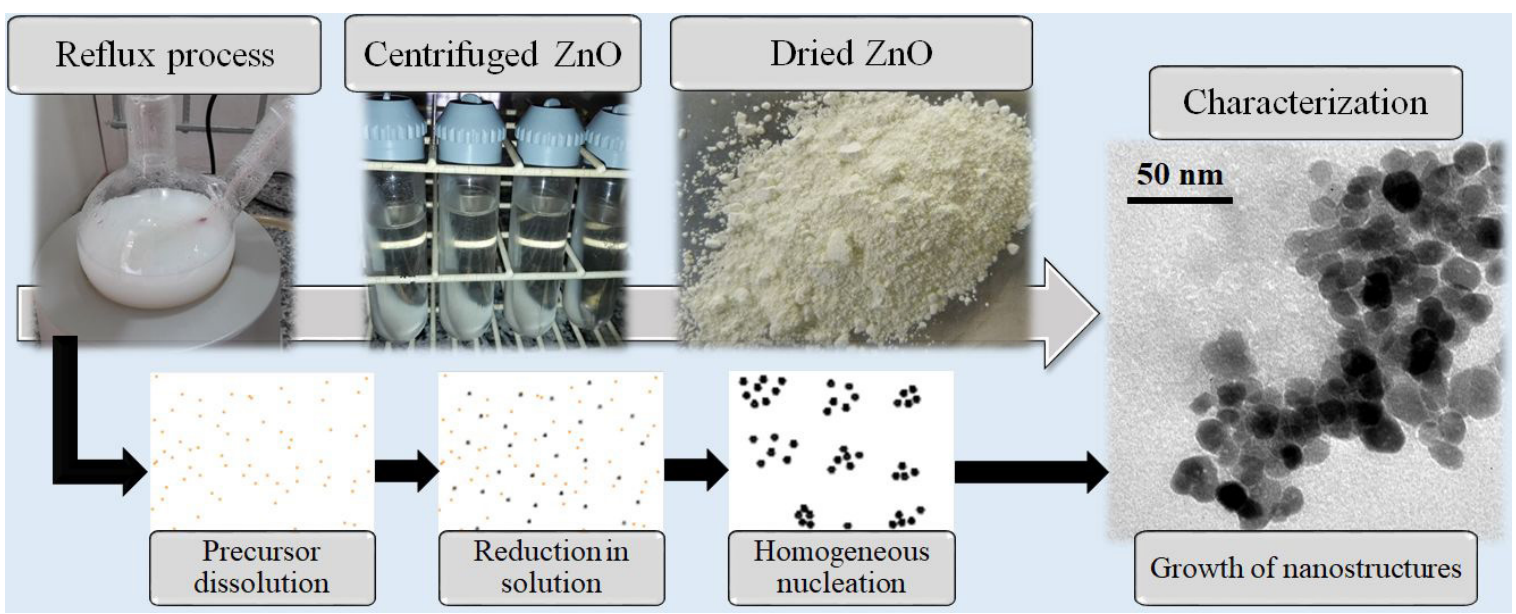

Figure 1. Simplified process for obtaining nanostructured zinc oxide in polyol medium.

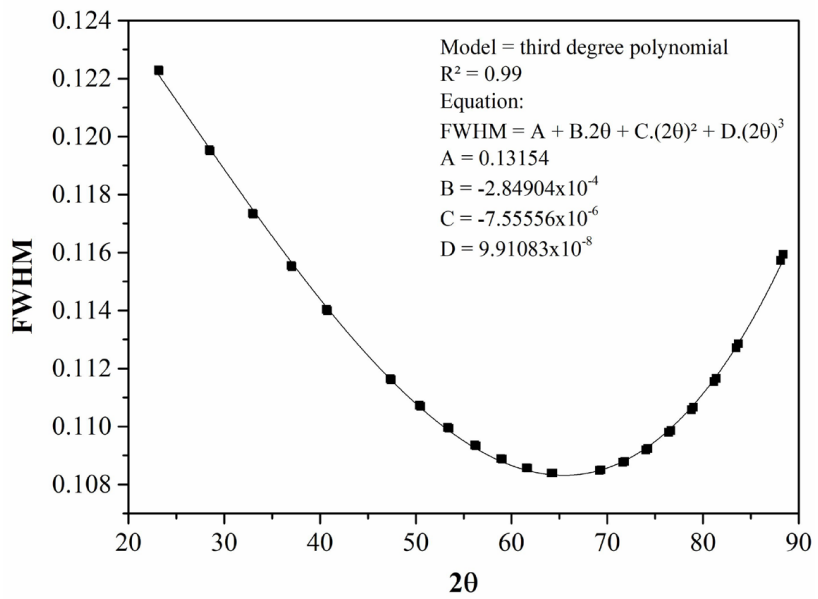

Figure 2. Instrumental broadening result of silicon, refinement was performed by the Rietveld method with the aid of Fullprof software. 


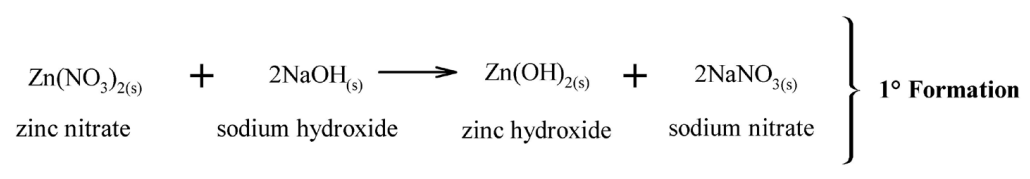

$$
\left.\underset{\text { zinc hydroxide }}{\mathrm{Zn}(\mathrm{OH})_{2(\mathrm{~s})} \stackrel{\Delta}{\longrightarrow} \underset{\substack{\text { zinc oxide } \\ \mathrm{ZnO}_{(\mathrm{s})}}}{\longrightarrow}+\mathrm{H}_{2} \mathrm{O}_{(\mathrm{L})}}\right\} \mathbf{2}^{\circ} \text { Decomposition }
$$

Figure 3. Steps stoichiometric $\mathrm{ZnO}$ formation by polyol method.

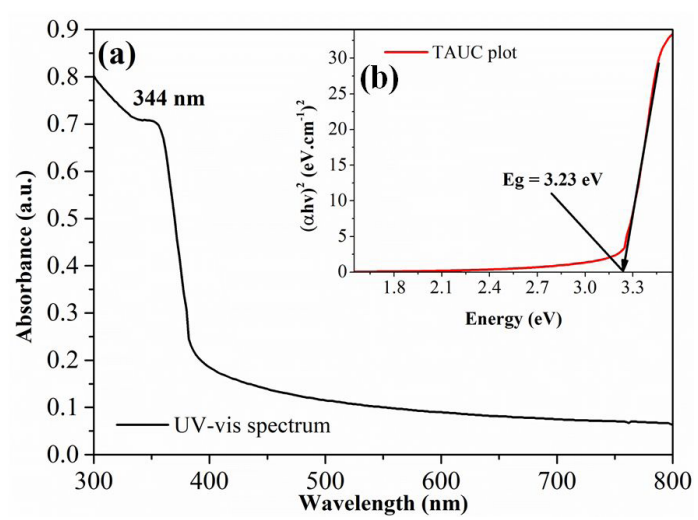

Figure 4. (a) UV-visible spectrum of the nanostructured $\mathrm{ZnO}$ and (b) TAUC plot result.

distribution was determined by the dynamic light scattering (DLS) technique on the NANO-flex ${ }^{\circledR} 180^{\circ} \mathrm{DLS}$, at $25^{\circ} \mathrm{C}$.

The surface area and pore volume of the $\mathrm{ZnO}$ powder sample, determined by the Brunauer, Emmett and Teller (BET) technique, was performed on the Quantachrome Instruments, Nova $1200 \mathrm{e}$ model. The sample was degassed at $80{ }^{\circ} \mathrm{C}$ for $20 \mathrm{~h}$ before analysis. Additionally, the particle size was estimated by the equation:

$$
d_{B E T}=\frac{6000}{A s . \rho}
$$

where $A s$ is the surface area of the $\mathrm{ZnO}$ powder sample e $\rho$ is the specific mass of $\mathrm{ZnO}\left(5.67 \mathrm{~g} \mathrm{~cm}^{-3}\right)$.

\section{Results and Discussion}

\subsection{Synthesis process of $\mathrm{ZnO}$}

The results show that the use of $\mathrm{Zn}\left(\mathrm{NO}_{3}\right)_{2}$ combined with $\mathrm{NaOH}$ ensures a simple process for $\mathrm{ZnO}$ synthesis in nanoscale and with uniformity of its structure. By removing the $\mathrm{NaOH}$ addition from the steps, it was verified that $\mathrm{ZnO}$ formation does not occur. Thus, $\mathrm{NaOH}$ has the function of facilitating the obtaining of nanostructures and to ensure the formation, in an earlier stage, of $\mathrm{Zn}(\mathrm{OH})_{2}$. Figure 3 shows some steps of the synthesis as well as the final nanoparticulate product.

In this synthesis, the first equation concerns the double exchange that occurred between $\mathrm{Zn}\left(\mathrm{NO}_{3}\right)_{2}$ and $\mathrm{NaOH}$ (at $23{ }^{\circ} \mathrm{C}$ ), forming $\mathrm{Zn}(\mathrm{OH})_{2}$. During the reflux process, the solution remained heated for $4 \mathrm{~h}$, when the thermal degradation of ethylene glycol may have occurred to a small extent $^{35}$. The second equation concerns the formation of $\mathrm{ZnO}$ particles, which occurred due to the heating of the solution that decomposes zinc hydroxide into nanoparticulate zinc oxide.

\subsubsection{Optical study}

UV-vis spectra provides the information about the excitonic and intertransition of nanomaterials. Figure $4 \mathrm{a}$ shows the UV-visible molecular absorption spectrum of the obtained nanostructured $\mathrm{ZnO}$. It was detected an absorption band in the spectrum at $344 \mathrm{~nm}$, which is a characteristic band for $\mathrm{ZnO}$ confirmed by literature ${ }^{29,36-38}$. The absence of any other band in the spectrum confirms that the synthesized product is formed only by zinc oxide. Due to the nanodimensions, $\mathrm{ZnO}$ sample exhibit blue shifted absorbance peak when compared to its bulk that has the absorbance band at $386 \mathrm{~nm}$ at room temperature ${ }^{11}$.

Based on the UV-visible spectrum, it was also possible to determine the optical band gap energy by applying the Tauc plot method, Figure 4b. The result found was $3.23 \mathrm{eV}$, similar to the ones already reported ${ }^{37,39}$.

\subsection{Crystallinity and phases}

Figure 5a presents the diffractogram from X-ray diffraction of the zinc oxide powder synthesized. All diffraction peaks are related to the hexagonal wurtzite phase of the zinc oxide, with space group $P 6_{3} m c$, according to the standard diffractogram ICSD 180050 . No other peaks of any other phases were observed, what proves that monophasic wurtzite zinc oxide nanoparticles were obtained.

Figure $5 \mathrm{~b}$ shows the XRD refined data by the Rietveld method. As result, the size of the crystallite was approximately $12 \mathrm{~nm}$. This result is close to the average particle size found in DLS, FESEM and TEM analyses, leading us to believe that the characterization in the different methods was performed successfully.

In the study of Nithiya et al. ${ }^{40}$ the crystallite size of $\mathrm{ZnO}$ sample, also obtained by the polyol method, in a synthesis that lasted $5 \mathrm{~h}$ at a temperature of $100{ }^{\circ} \mathrm{C}$, was estimated in $35 \mathrm{~nm}$. In another study, the size of the crystallite was estimated between 21 and $46 \mathrm{~nm}$ using zinc acetate as precursor salt, with synthesis temperature set at $150{ }^{\circ} \mathrm{C}$ and reaction time up to $5 \mathrm{~h}^{41}$.

\subsection{Morphology and particles size}

Figures 6 and 7 show the morphologies of the nanostructured $\mathrm{ZnO}$ obtained by FESEM and TEM, being the average particle size of 20 and $14 \mathrm{~nm}$, respectively. The adsorption and desorption isotherms, obtained 

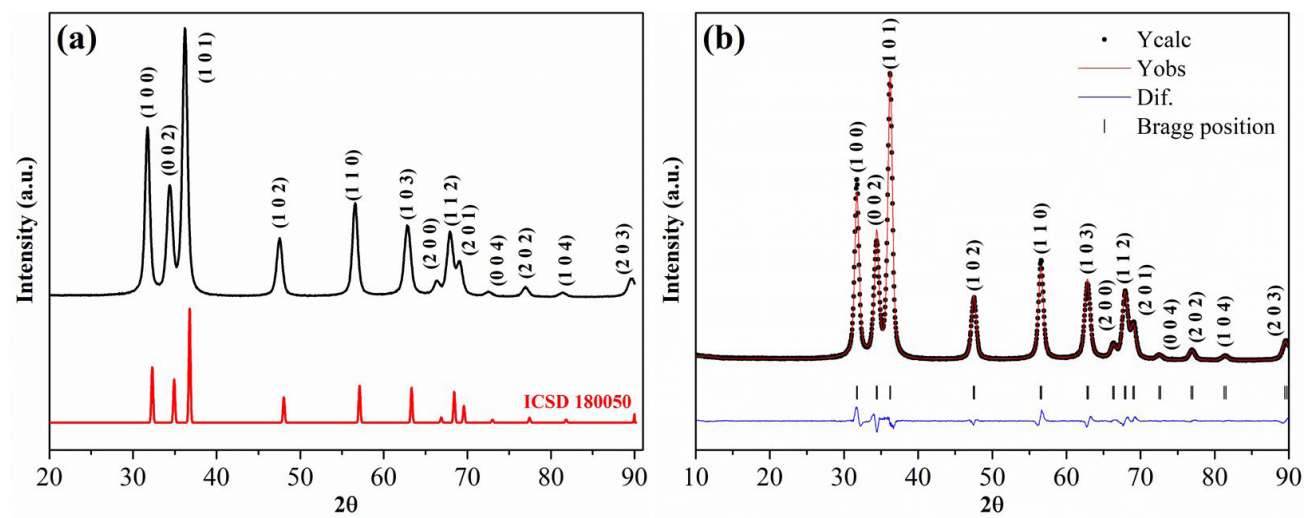

Figure 5. (a) XRD diffractogram of the $\mathrm{ZnO}$ powder sample and (b) refinement result by Rietveld method.

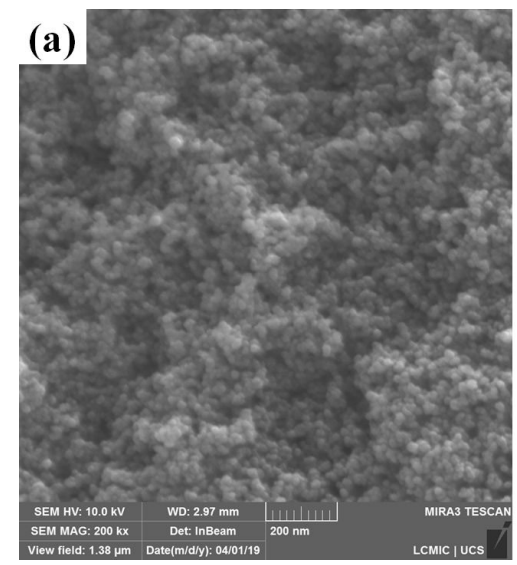

\section{(b)}

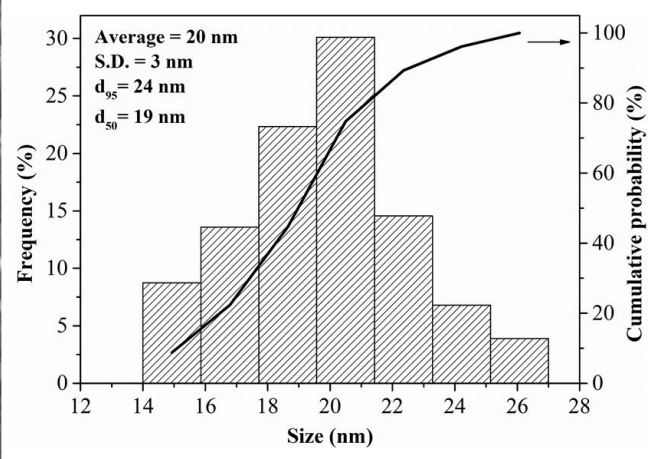

Figure 6. (a) Analysis by FESEM and (b) particles distribution for $\mathrm{ZnO}$ sample.

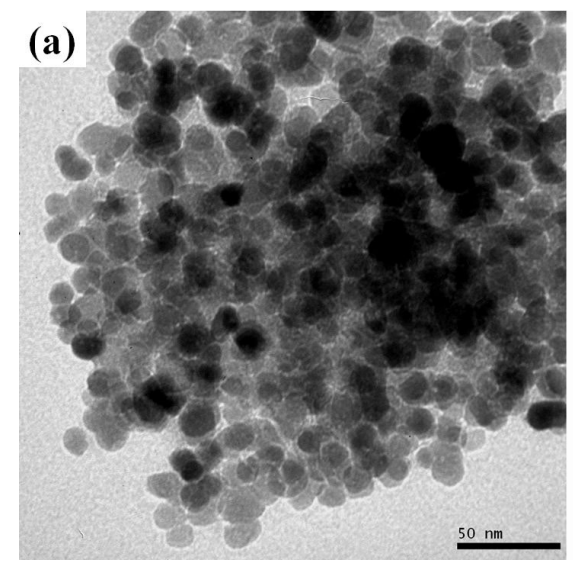

(b)

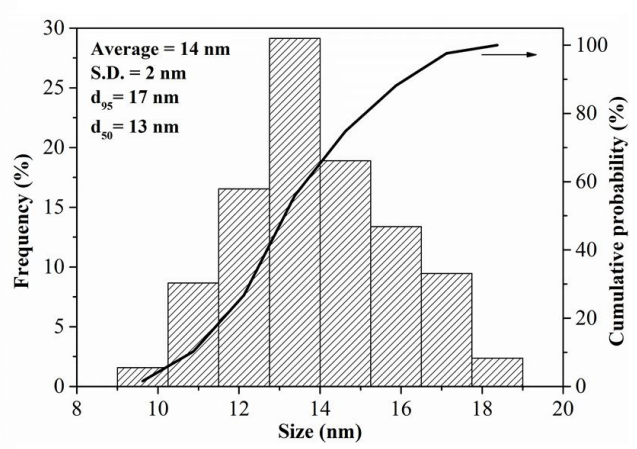

Figure 7. (a) Analysis by TEM and (b) particles distribution for $\mathrm{ZnO}$ sample.

by BET technique, have an acute stage of capillary condensation at high relative pressure, which belong to the type IV isotherm, according to the IUPAC classification, Figure 8 . The surface area of $54.2 \mathrm{~m}^{2} \mathrm{~g}^{-1}$ and pore volume of $0.31 \mathrm{~cm}^{3} \mathrm{~g}^{-1}$ were determined. The surface area value allowed to determine the average particle size, which was $20 \mathrm{~nm}$ corroborating to the other techniques applied in this study. The particles are considered agglomerated if the particle size determined by BET is greater than the size of the crystallite so, the larger the difference the higher degree of agglomeration of the particles. Similar results of surface area were found in the paper presented by Efa and Imae $\mathrm{e}^{39}, 51.5$ and $55.7 \mathrm{~m}^{2} \mathrm{~g}^{-1}$.

The ethylene glycol, with its structure and more voluminous functional groups $(\mathrm{OH})$, proved to act as a limiting agent of 

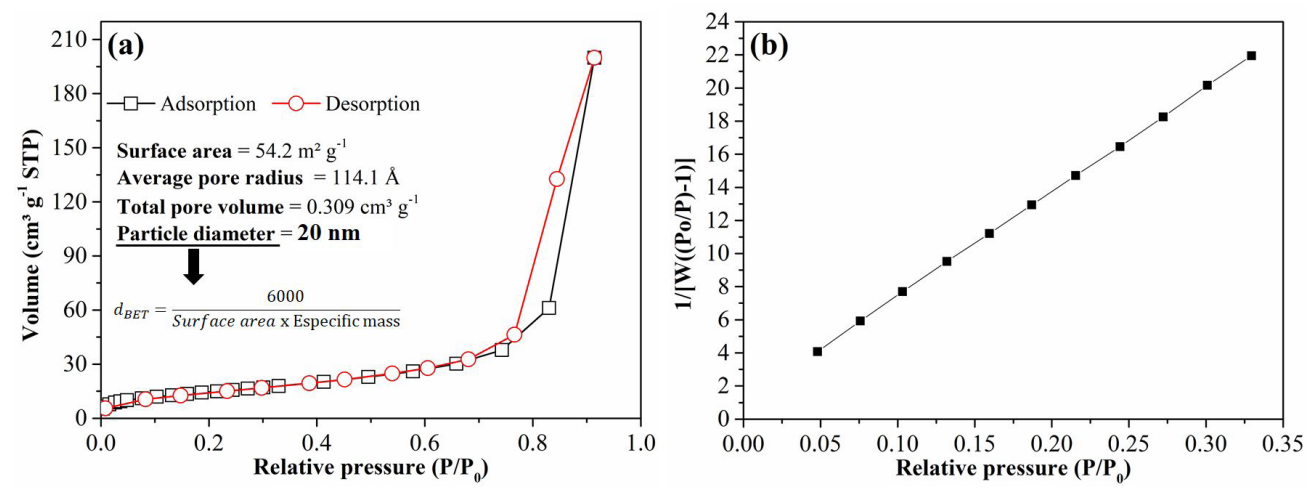

Figure 8. (a) Nitrogen adsorption-desorption isotherms and (b) BET curve of the obtained nanostructured $\mathrm{ZnO}$.

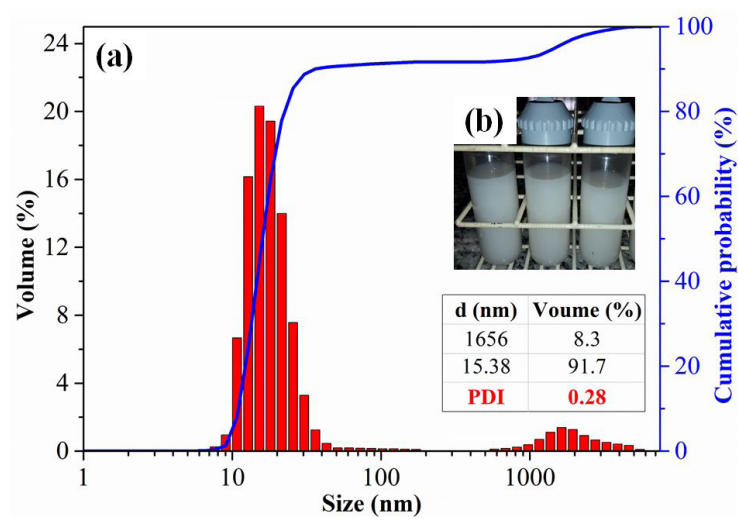

Figure 9. (a) Particle size distribution examined by DLS analysis and (b) colloidal suspension of $\mathrm{ZnO}$.

the growth of the crystal planes. Consequently, more uniform dimensional shapes, such as spheres, were produced ${ }^{38}$.

In the DLS analysis, Figure 9a, an average particle size value of $15 \mathrm{~nm}$ was found, which corresponded to $91.7 \%$ of the total volume of the sample analyzed. Table 1 shows a summary of the $\mathrm{ZnO}$ particles size obtained by the different characterization techniques used in this study. As can be seen, the results from the different techniques were similar, indicating that the proposed method is effective in obtaining nanoparticles with a size in the range of $20 \mathrm{~nm}$. The Figure $9 \mathrm{~b}$ shows the white-colored colloidal solution of the nanostructured $\mathrm{ZnO}$ obtained.

In the work presented by Chieng and $\operatorname{Loo}^{29}$, by using zinc acetate dehydrate as the salt precursor, they obtained spherical $\mathrm{ZnO}$ nanostructures with an average size of $19.62 \mathrm{~nm}$, but by applying a higher temperature $\left(160^{\circ} \mathrm{C}\right)$ and for a longer time, $12 \mathrm{~h}$. So, herein, we present a brander and faster synthesis for the same aim.

\section{Conclusion}

Zinc oxide nanostructures were prepared by the combination of zinc nitrate with sodium hydroxide in polyol medium. Ethylene glycol was used as solvent and, by increasing the temperature $\left(140{ }^{\circ} \mathrm{C}\right)$, promoted the decomposition of $\mathrm{Zn}(\mathrm{OH})_{2}$ into $\mathrm{ZnO}$ nanoparticulate.
Table 1. Result of particle size by different techniques.

\begin{tabular}{cc}
\hline Analysis & Value $(\mathrm{nm})$ \\
\hline SEM & 20 \\
\hline TEM & 14 \\
\hline XRD & 12 \\
\hline BET & 20 \\
\hline DLS & 15
\end{tabular}

The UV-visible spectrum showed absorption band at $344 \mathrm{~nm}$ with a band gap of $3.23 \mathrm{eV}$, both characteristics of the nanostructured $\mathrm{ZnO}$. The particles presented an average size of $14 \mathrm{~nm}$ and a crystallite size of $12 \mathrm{~nm}$. FESEM, DLS and BET results presented similar sizes, 20, 15 and $20 \mathrm{~nm}$, respectively. BET analysis showed surface area of $54.2 \mathrm{~m}^{2} \mathrm{~g}^{-1}$ with a pore volume of $0.31 \mathrm{~cm}^{3} \mathrm{~g}^{-1}$. The results presented in this study reveal a new alternative for $\mathrm{ZnO}$ nanoparticulate synthesis that, due to its particle size quite competitive, leads to the possibility of several applications in nanotechnology, such as advanced ceramics, solar cells and antimicrobial agent.

\section{Acknowledgments}

National Council for Scientific and Technological Development $(\mathrm{CNPq})$ of Brazil. Microscopy and Microanalysis Center (CMM) of UFRGS.

\section{References}

1. Salah N, AL-Shawafi WM, Alshahrie A, Baghdadi N, Soliman YM, Memic A. Size controlled, antimicrobial $\mathrm{ZnO}$ nanostructures produced by the microwave assisted route. Mater Sci Eng C. 2019;99:1164-73.

2. Kaushik M, Niranjan R, Thangam R, Madhan B, Pandiyarasan $\mathrm{V}$, Ramachandran $\mathrm{C}$, et al. Investigations on the antimicrobial activity and wound healing potential of $\mathrm{ZnO}$ nanoparticles. Appl Surf Sci. 2019;479:1169-77.

3. Popov AP, Priezzhev AV, Lademann J, Myllylä R. Alteration of skin light-scattering and absorption properties by application of sunscreen nanoparticles: a Monte Carlo study. J Quant Spectrosc Radiat Transf. 2011;112(11):1891-7.

4. Saleh SM. ZnO nanospheres based simple hydrothermal route for photocatalytic degradation of azo dye. Spectrochim Acta A Mol Biomol Spectrosc. 2019;211:141-7. 
5. Álvarez D, Collazo A, Nóvoa XR, Pérez C. Assessment of ZnO nanoparticles as anticorrosive pigment in hybrid sol-gel films. Prog Org Coat. 2016;96:3-12.

6. Sokovnin SY, Il'ves VG, Khrustov VR, Zuev MG. Investigation of properties of $\mathrm{ZnO}$ ceramics sintered from $\mathrm{ZnO}-\mathrm{Zn}$ nanopowders produced by pulsed electron beam evaporation. Ceram Int. 2017;43(14):10637-44

7. Luo J, Wang Y, Zhang Q. Progress in perovskite solar cells based on ZnO nanostructures. Sol Energy. 2018;163:289-306.

8. Ubani CA, Ibrahim MA. Complementary processing methods for $\mathrm{ZnO}$ nanoparticles. MaterialsToday. Proceedings. 2019;7(Pt 2):646-54.

9. Kathalingam A, Park HC, Kim SD, Kim HS, Velumani S, Mahalingam T. Synthesis of $\mathrm{ZnO}$ nanorods using different precursor solutions and their two terminal device characterization. J Mater Sci Mater Electron. 2015;26(8):5724-34.

10. Kathalingam A, Chae YS, Rhee JK. Synthesis of multilinked $\mathrm{ZnO}$ rods by microwave heating. Cryst Res Technol. 2011;46(5):517-22.

11. Diallo A, Ngom BD, Park E, Maaza M. Green synthesis of $\mathrm{ZnO}$ nanoparticles by Aspalathus linearis: Structural \& optical properties. J Alloys Compd. 2015;646:425-30.

12. Sharmila G, Thirumarimurugan M, Muthukumaran C. Green synthesis of $\mathrm{ZnO}$ nanoparticles using Tecoma castanifolia leaf extract: characterization and evaluation of its antioxidant, bactericidal and anticancer activities. Microchem J. 2019;145:578-87.

13. Rathore N, Sarkar SK. Effect of different anions on $\mathrm{ZnO}$ morphology. Energy Procedia. 2014;54:771-76.

14. Sahu K, Choudhary S, Singh J, Kuriakose S, Singhal R, Mohapatra $\mathrm{S}$. Facile wet chemical synthesis of $\mathrm{ZnO}$ nanosheets: effects of counter ions on the morphological, structural, optical and photocatalytic properties. Ceram Int. 2018;44(18):23094-101.

15. Moballegh A, Shahverdi HR, Aghababazadeh R, Mirhabibi AR. $\mathrm{ZnO}$ nanoparticles obtained by mechanochemical technique and the optical properties. Surf Sci. 2007;601(13):2850-4.

16. Chen W, Yao C, Gan J, Jiang K, Hu Z, Lin J, et al. ZnO colloids and $\mathrm{ZnO}$ nanoparticles synthesized by pulsed laser ablation of zinc powders in water. Mater Sci Semicond Process. 2020;109:104918

17. Medina A, Béjar L, Borjas SE, Zarate J, Vargas R, Herrera $\mathrm{G}$, et al. Characterization of $\mathrm{ZnO}$ nanoparticles with shortbar shape produced by chemical precipitation. Mater Lett. 2012;71:81-3.

18. Erazo A, Mosquera SA, Rodríguez-Paéz JE. Synthesis of $\mathrm{ZnO}$ nanoparticles with different morphology: study of their antifungal effect on strains of Aspergillus niger and Botrytis cinerea. Mater Chem Phys. 2019;234:172-84.

19. Maruthupandy M, Zuo Y, Chen JS, Song JM, Niu HL, Mao $\mathrm{CJ}$, et al. Synthesis of metal oxide nanoparticles $(\mathrm{CuO}$ and $\mathrm{ZnO}$ NPs) via biological template and their optical sensor applications. Appl Surf Sci. 2017;397:167-74.

20. Kiran Kumar ABV, Saila ES, Narang P, Aishwarya M, Raina R, Gautam M, et al. Biofunctionalization and biological synthesis of the $\mathrm{ZnO}$ nanoparticles: the effect of Raphanus sativus (white radish) root extract on antimicrobial activity against MDR strain for wound healing applications. Inorg Chem Commun. 2019;100:101-6.

21. Hong R, Pan T, Qian J, Li H. Synthesis and surface modification of $\mathrm{ZnO}$ nanoparticles. Chem Eng J. 2006;119(2-3):71-81.

22. Wojnarowicz J, Chudoba T, Koltsov I, Gierlotka S, Dworakowska $\mathrm{S}$, Lojkowski W. Size control mechanism of $\mathrm{ZnO}$ nanoparticles obtained in microwave solvothermal synthesis. Nanotechnology. 2018;29(6):065601.

23. Wojnarowicz J, Opalinska A, Chudoba T, Gierlotka S, Mukhovskyi R, Pietrzykowska E, et al. Effect of water content in ethylene glycol solvent on the size of $\mathrm{ZnO}$ nanoparticles prepared using microwave solvothermal synthesis. Journal of Nanomaterials. 2016;2016:2789871.

24. Jianzhong M, Liu J, Bao Y, Zhu Z, Liu H. Morphologyphotocatalytic properties-growth mechanism for $\mathrm{ZnO}$ nanostructures via microwave-assisted hydrothermal synthesis. Cryst Res Technol. 2013;48(4):251-60.

25. Lee S, Jeong S, Kim D, Hwang S, Jeon M, Moon J. ZnO nanoparticles with controlled shapes and sizes prepared using a simple polyol synthesis. Superlattices Microstruct. 2008;43(4):330-9.

26. Zhang A-Q, Zhang L, Sui L, Qian D-J, Chen M. Morphologycontrollable synthesis of $\mathrm{ZnO}$ nano-/micro- structures by a solvothermal process in ethanol solution. Cryst Res Technol. 2013;48(11):947-55.

27. Cimitan S, Albonetti S, Forni L, Peri F, Lazzari D. Solvothermal synthesis and properties control of doped $\mathrm{ZnO}$ nanoparticles. J Colloid Interface Sci. 2009;329(1):73-80.

28. Qi K, Xing X, Zada A, Li M, Wang Q. Liu S yuan, Lin H, Wang G. Transition metal doped $\mathrm{ZnO}$ nanoparticles with enhanced photocatalytic and antibacterial performances: experimental and DFT studies. Ceram Int. 2020;46(2):1494-502.

29. Chieng BW, Loo YY. Synthesis of $\mathrm{ZnO}$ nanoparticles by modified polyol method. Mater Lett. 2012;73:78-82.

30. Dong X, Zhang A, Yang P. Synthesis of $\mathrm{ZnO}$ microstructures in glycerol/water solution. Ceram Int. 2014;40:141-8.

31. Dean JA. Lange's handbook of chemistry. 15th ed. New York: McGraw- Hill; 1999.

32. Grisaru H, Palchik O, Gedanken A, Palchik V, Slifkin MA, Weiss AM. Microwave-assisted polyol synthesis of CuInTe2 and CuInSe2 nanoparticles. ChemInform. 2004;35(2):7148-55.

33. Vázquez M. Magnetic nano- and microwires: design, synthesis, properties and applications. 1st ed. Cambridge: Woodhead Publishing; 2015.

34. Ficai D, Grumezescu A. Nanostructures for novel therapy synthesis, characterization and applications. 1st ed. New York: Elsevier; 2017.

35. Fievet F, Lagier JP, Blin B, Beaudoin B, Figlarz M. Homogeneous and heterogeneous nucleations in the polyol process for the preparation of micron and submicron size metal particles. Solid State Ion. 1989;32-33(Pt 1):198-205.

36. Farooqi MMH, Srivastava RK. Structural, optical and photoconductivity study of $\mathrm{ZnO}$ nanoparticles synthesized by annealing of ZnS nanoparticles. J Alloys Compd. 2017;691:27586.

37. Bhatia S, Verma N. Photocatalytic activity of $\mathrm{ZnO}$ nanoparticles with optimization of defects. Mater Res Bull. 2017;95:468-76.

38. Mezni A, Kouki F, Romdhane S, Warot-Fonrose B, Jouli S, Mlayah A, et al. Facile synthesis of $\mathrm{ZnO}$ nanocrystals in polyol. Mater Lett. 2012;86:153-6.

39. Efa MT, Imae T. Hybridization of carbon-dots with $\mathrm{ZnO}$ nanoparticles of different sizes. Journal of the Taiwan Institute of Chemical Engineers. 2018;92:112-7.

40. Nithiya P, Chakra CHS, Ashok C. Synthesis of TiO2 and ZnO nanoparticles by facile polyol method for the assessment of possible agents for seed germination. MaterialsToday. Proceedings. 2015;2:4483-88.

41. Alves TEP, Kolodziej C, Burda C, Franco A. Effect of particle shape and size on the morphology and optical properties of zinc oxide synthesized by the polyol method. Mater Des. 2018;146:125-33 